Psychiatric Bulletin (2005), 29, 441-445

MICHAEL CLARK AND CLAIR CHILVERS

\title{
Mental health research system in England: yesterday, today and tomorrow* ${ }^{* \dagger}$
}

Now is an opportune time to review the organisation of mental health research in England. Significant changes in National Health Service (NHS) research and development (R\&D) have occurred in general and some are specific to mental health. Further developments are beginning and are planned for the near future. To make the most of these, it is important that the mental health research community (academics, funders of research, service users, carers, policy makers and healthcare and social care staff) has a stake in how the system progresses.

In this paper we will place mental health research into context by briefly reviewing how NHS R\&D has developed in recent years. We will consider what we know about the state of mental health research within this context. This paper takes up themes set out by Chilvers et al (2005), but will expand upon them in terms of a model for understanding the organisation of health research, namely the health research system model (Pang et al, 2003). This model helps to develop a holistic perspective on current developments, and to consider the future needs for mental health $R \& D$. We will touch upon future needs towards the end of the paper.

\section{Mental health research system of yesterday}

\section{Context of NHS R\&D}

Mental health R\&D operates across a number of systems, one of the major ones being that of NHS R\&D. From its inception, and for over 40 years since, a laissez-faire approach to R\&D in the NHS prevailed. The settlement allowed, chiefly, the medical profession to direct research resources as they, as individuals or small groups, felt fit (Kirk, 2001). Although it was acknowledged that this had led to great strides forward in improving the knowledge base of significant parts of healthcare, there was concern that the whole never satisfactorily matched up to the sum of its parts (Kirk, 2001). The House of Lords Select Committee on Science and Technology (1988), for example, criticised the NHS for failing to set out its research needs and to address shortcomings in implementation of research. This latter failing was felt to contribute greatly to wide variations in service delivery and, thus, the health of the nation (Kirk, 2001).

The subsequent appointment of the NHS's first National Director of R\&D, Professor Sir Michael Peckham, led to a new strategic direction for NHS R\&D aimed at addressing the identified shortcomings (Peckham, $1991 a, b)$. The following years saw work and progress to introduce greater national coherence and accountability in how research resources are used in the NHS (Culyer, 1994; Central Research and Development Committee of the Department of Health, 1999; Department of Health, 2000).

The development of a more coordinated strategic vision for NHS R\&D has been seen as positive, but it is recognised that more remains to be done (Baker, 2001a,b; Kirk, 2001). Moving to research networks involving more integration of NHS organisations, universities and other stakeholder groups is one step being taken to direct further improvement (Baker, 2001a; Research for Patient Benefit Working Group, 2004).

\section{Recent history of mental health NHS R\&D}

For a long time mental health $R \& D$ has operated as a fragmented component of NHS R\&D, with small groups trying to find their own ways in that world. The Clarke review of NHS R\&D (Central Research and Development Committee, 1999) established multidisciplinary topic groups to address the R\&D needs and priorities in each of six priority health areas: cancer; cardiovascular disease and stroke; ageing; primary care; accidents; and mental health. The Mental Health Topic Working Group (Department of Health, 1999a) reported specific research recommendations for its area. Following this review, national directors for R\&D were appointed for the portfolios of cancer, cardiovascular disease and mental health. This was the first opportunity for somebody in England to provide a national strategic lead for mental health R\&D.

The starting point for developing a clearer national strategy was to review the current state of mental health R\&D. The Department of Health (2002) document provided an overview of many aspects of mental health research. The report was based on surveys of NHS trusts
*The views expressed in this article are those of the authors and do not necessarily represent the views of the Department of Health.

†See pp. 446-448, this issue. 
an

editorial and social service departments, and the views of a service user panel. National Health Service trusts were asked to report on research in mental health, if they spent more than $f 50000$ per annum on this topic. There were 60 trusts which reported that they met this criterion. Key findings from this report were:

(a) The best estimate of the (then) level of spending on mental health research by the NHS was $f 129$ million. This and other evidence pointed to a large quantity of mental health research activity. There was also evidence of significant partnership working across the NHS and with universities.

(b) Only 221 projects ( $11 \%$ of all mental health projects) had external funding of at least $f 150000$, including 31 randomised controlled trials ( $2 \%$ of the total projects). The main funders of these were the Department of Health, the Medical Research Council (MRC) and the Wellcome Trust. Some 40\% of the identified projects were described by trusts as 'own account', i.e. they had no significant external funding

(c) There was a lack of systematic reviews for mental health.

(d) There were over 3000 active research staff in mental health, with over 1000 working towards higher degrees.

(e) In terms of the National Service Framework (NSF) for Mental Health (Department of Health, 1999b), standards lacking focused research activity were those of health promotion, access to care and support for carers.

More insights into the state of mental health research have been added by reviewing the mental health research programmes in the annual reports of $R \& D$ submitted by trusts to the Department of Health. This reflects the picture above of a great deal of good activity and partnerships, but also much small-scale research, gaps in relation to the standards of the NSF and opportunities for further collaboration.

In summary, NHS R\&D in mental health in England was for a long time left with little nationally coordinated direction. Research in this context was a dispersed activity, and, as such, we had little detailed knowledge of the state of that research community, its impact, needs and potential. Developing better intelligence on the state of mental health R\&D enabled better strategic developments to improve the situation.

\section{Mental health research system of today}

\section{What is a health research system?}

To better understand the role and potential of research in a health system, the model of a health research system has been described (Pang et al, 2003) and is continuing to be developed (Sadana \& Pang, 2004). The aims of the model include allowing individual countries to better describe, analyse and organise their health research activities.
A health research system is defined as:

'The people, institutions, and activities whose primary purpose is to generate high quality knowledge that can be used to promote, restore and/or maintain the health status of populations. It can include the mechanisms adopted to encourage the utilization of research'. (Sadana \& Pang, 2004, p. 352).

The four functions required in this system, and their operational components, have been defined as (Pang et al, 2003; Sadana \& Pang, 2004):

(a) Stewardship - the articulating of a vision and strategy; identifying the priorities and coordinating adherence to them; setting and monitoring ethical standards for the system; monitoring and evaluating the system.

(b) Financing - securing research funds and allocating them accountably.

(c) Creating and sustaining resources - strengthening and sustaining the human and physical capacity to conduct and absorb research.

(d) Producing and using research - producing scientifically validated research outputs; translating and communicating research to inform health policy, practice and public opinion; promoting the use of research to develop interventions and technologies to improve health (drugs, vaccines, devices, etc.).

\section{Current state of the mental health research system}

We will review the four functions of a health research system in relation to recent and ongoing work to improve mental health research in England. It should be noted that the ideas and concept of 'system' cover mental health across the ages.

\section{Stewardship}

The Department of Health's appointment of a portfolio director for mental health R\&D provided the first opportunity for a coordinated stewardship of the mental health research system. The stakeholders involved in this research system can now be drawn together to jointly articulate a vision and strategy. This will have to happen within the framework of other systems, notably the NHS (including its R\&D) and higher education.

As the Department of Health monitors and evaluates the broader health research system, we work to ensure that mental health research is considered in its own right and in relation to other health priorities. One of the main recent developments is the establishment of the UK Clinical Research Collaboration (UKCRC; http://www.ukcrc. org; Research for Patient Benefit Working Group, 2004; UK Clinical Research Collaboration, 2004) by the government in response to concerns about the general state of clinical research in England (Academy of Medical Sciences, 2003; Bioscience Innovation and Growth Team, 2003). This body is responsible for steering (or providing stewardship to) the national development of clinical research in general. The mental health research community is in the process of establishing its relationship with the UKCRC. 
In addition, much of the regulatory and ethics frameworks for mental health research is set within the general health research system of England. (We include within this, developments beyond the UK, such as the European Directive on Clinical Trials, as they are mediated through national policy-making.) The Research Governance Framework for Health and Social Care (Department of Health, 2005) is the most notable component of this. In their stewardship role of the national health research system, the Department of Health (and now the UKCRC) review regulation of research, and we endeavour to ensure that specific heed is paid to mental health research concerns.

Yet these wider research system developments still leave significant scope, and need, to establish a strategy specifically for mental health research. Through the stewardship role, we can now collate intelligence about the system to ensure the strategy develops in a more informed way. Although the Department of Health continues to lead on this, we recognise that it cannot develop the strategy in isolation. As such, we are working with others to improve our knowledge of the mental health research system. A key element of this shared work is to establish agreed national priorities for mental health research. Some work has already been undertaken (see, for example, the Mental Health Topic Working Group of the Clarke review discussed above, Thornicroft et al (2002), and the 5 year review of the National Service Framework for Mental Health (Department of Health, 2004)). At the time of writing, further national consultations have begun on mental health research priorities across all ages.

\section{Financing}

Although work has continued to secure more resources for mental health R\&D, a key task has been to understand better what resources we presently have, how they are used, and what the gaps are. The reviews of mental health discussed above have gone a long way to improving our intelligence on this matter. To take this further, however, the Mental Health Funders Group (comprising the main funders of mental health research for the UK) is undertaking a strategic analysis of mental health research across all of the main funders of mental health research. This includes the research councils, the Department of Health's research programmes and the charitable sector. It is similar to the analysis undertaken of cancer research (National Cancer Research Institute, 2002)

Once the strategic analysis is completed, member organisations of the Mental Health Funders Group can review their spending on mental health research, both as individual organisations and collectively. We can then continue the task of securing and accountably allocating funding from a more informed position. It has been argued, for example, that relative to the burden of disease, mental health receives a low level of research funding compared with other illnesses (Buckle, 2004). The same report noted that relative to other health areas, notably cancer, mental health does not have a strong charitable base for its research funding.

\section{Creating and sustaining resources}

We commented above on the low level of large-scale research in mental health. This is despite the fact that there are both ideas and demand for clinical trials in mental health. Buckle (2004), for example, noted that applications to the MRC for funding of clinical trials in the area of mental health were second only to cancer, but that the proportion finally funded was low, being $4 \%$ for mental health and $11 \%$ for cancer.

Part of the reason for this low level of large-scale research in mental health was probably the lack of an infrastructure on which to run such projects, particularly clinical trials. This may have reduced the ability of mental health researchers to secure funding for large projects to provide the evidence needed to drive service improvements. Hence, the National Institute for Mental Health in England (NIMHE; http://www.nimhe.org.uk) included research as a core activity and established the Mental Health Research Network (MHRN; http:// www.mhrn.info). This comprises 'research hubs' across England that are collaborations of clinical sites, universities, service users and carers organised through a local coordinating centre. If the MHRN adopts a project, the hubs are there to help recruit participants. This infrastructure should place mental health researchers in a better position to compete for budgets to support larger-scale research. The recent MRC call for research proposals for round two of its Brain Sciences Initiative has been successful for mental health, in part because of the existence of the MHRN.

In terms of the personnel to undertake research, it is recognised that there is more to do. The MRC, for example, found that the number of applications for its fellowships was comparatively low in mental health, but the success rate of applicants was high (Buckle, 2004). Mental health needs to make better use of these more generic funding opportunities, such as the fellowships funded by the Department of Health through its Research Capacity Development Programme.

A further concern arises from the Council of Heads of Medical Schools' report (2004) on clinical academic posts. This noted that clinical academic posts in general have declined in number, but that psychiatry was one of the worst affected medical disciplines. We need to improve our nurturing of the academics and researchers of the future.

\section{Producing and using research}

The UK has a strong reputation for publications from mental health research. An international bibliometric analysis across 15 industrialised countries (Lewison \& Wilcox-Jay, 2002) showed that UK publications were above the average for citations. Although the number of publications is by no means the only measure of research activity and its impact, this information provides useful insights. For example, in comparison with other countries, the UK was found to have particularly strong publication commitment in the areas of primary healthcare, learning disability, evidence-based practice and forensic mental health. Its weakest publication areas were substance 


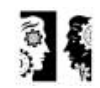

editorial misuse, user involvement and dual diagnosis. Reviewing relative publication commitment to specific mental health areas can show areas that need more attention and areas where there may be potential for greater international collaboration.

Through identifying the research priorities to inform policy and then working with the funders of research, we are beginning to see more synergy between research and policy. We also have a better infrastructure to plan and coordinate the dissemination of findings from research into practice. With its regional development centres, national fellows, other national and regional leads for topic areas, and its virtual infrastructure, NIMHE provides a potent resource for strengthening the link between research and development. Guidelines issued by the National Institute for Clinical Excellence (NICE) are also significant here. Through these activities we can move towards what has been called a 'policy community' (Black, 2001), in which there is better communication and understanding of each other across policy makers / implementers and researchers.

More has been done to make the mental health research community more inclusive. Service users are being involved far more in research at all of its stages. One significant illustration of this is the establishment of the Service User Research Group for England (SURGE) as another of the hubs of the MHRN. Plans are underway for similar involvement of carers. The development of a panel of peer reviewers within a high-security hospital by the National Forensic Mental Health R\&D Programme (http:// www.nfmhrp.org.uk) is an example of wider involvement of service users in mental health secure services.

It is also increasingly being recognised that mental health research can be more inclusive of other academic disciplines. This was acknowledged in a report of a recent workshop to discuss methodologies to evaluate complex interventions in mental health (National Institute for Mental Health in England, 2004). We now need to encourage and develop greater multidisciplinary collaboration in mental health research, using the fullest range of appropriate qualitative and quantitative methodologies.

\section{Mental health research system of tomorrow}

Having sketched a picture of the mental health research system of today, we recognise that this is only a beginning. We need to take forward each of the four functions within the system discussed above to build on the strengths and weaknesses already identified in UK mental health research. This can be done through a shared strategy for the mental health research community, but also within continuing wider developments, such as the UKCRC. When, for example, the UKCRC issues plans to address workforce issues in clinical research, for incentives for the NHS to engage in research, and the regulatory framework for research, it is sensible to make sure that the experiences of mental health professionals are heard and that the mental health research community is well placed to take full advantage of whatever opportunities are offered.

A significant development we need to capitalise on fully is the government's announcement of extra investment in R\&D in five areas, including mental health research. This will be used to increase the infrastructure, notably research networks, to support clinical research. Commissioning of research will be in large part directed by the research priorities and policy requirements being identified now, but there is still the challenge of attracting sufficient resources to run the desired largescale projects.

Having articulated a more coordinated approach to linking research, policy and practice/service development, we recognise two key points to address in this view of a mental health research system. The first is that of dissemination and prompt implementation of research findings into policy and practice (Department of Health, 2004). The Department of Health and NIMHE are collaborating on ideas to improve this area.

The second point to address is that of investigatordriven research, in which clinicians and academics can undertake smaller projects as a preliminary to larger scale research. It is a vital part of innovation and the future of mental health R\&D. The example of early intervention in psychosis is one that highlights this (Newton \& Birchwood, 2005). Although now established as part of the research, policy and service mainstreams, it has taken a long time for early intervention to achieve this. We need to find ways of ensuring that the innovative research of the future is supported. There is some support for small-scale, pilot and innovation research in the R\&D funding allocated to trusts. Nevertheless, it is recognised that there is still a problem of securing funding for new research areas, before they become sufficiently developed and accepted to secure large project funds (National Institute for Mental Health in England, 2004). This is an area for further thinking and development.

Drawing from the report on complex evaluations (National Institute for Mental Health in England, 2004), a further area where stewardship could pay dividends for everyone is that of methodological development. This report highlighted the benefits that can be gained from expanding the methodological framework and academic disciplines involved in mental health research. A broader consensus on appropriate methodologies, methods and tools for mental health research and evaluation across the mental health research community is likely to benefit everyone involved. Policy makers and practitioners may be more likely to see in results things that are relevant to them, rather than to highly controlled environments only. Researchers themselves may be better placed to compete for research funds if they cease denigrating each other's approaches. Finally, methodological development may help service users and carers to participate better in research and, thereby, know, understand and accept the evidence.

Another area that we should consider further developing is that of international links. Although some research has to be conducted in the specific context of interest, for example to allow for the particular 
characteristics of culture and care systems, other research results are more readily transportable across contexts. An obvious level to begin developing better collaboration on research is to ensure appropriate links between England, Scotland, Wales and Northern Ireland. Each of these countries is participating in several of the developments discussed above. We can look to better exchanges of ideas, resources and information with other countries further afield in due course.

\section{Conclusions}

We now have a timely opportunity and resources to take forward a national strategic approach to mental health research and development. Here, we have only been able to provide an aerial view of developments in the system for organising mental health research. There is more detail for each of the themes and initiatives we have discussed. More is needed in terms of knowledge about the system and developments to strengthen it. With the health research system model we have a framework to collectively guide our thinking and agree action to improve the organisation, relevance and impact of mental health research.

\section{Declaration of interest}

None.

\section{References}

ACADEMY OF MEDICAL SCIENCES (2003) Strengthening Clinical Research. London: AMS

BAKER, M. R. (2001a) R\&D in the new NHS. In Research and Development for the NHS: Evidence, Evaluation and Effectiveness (eds M. R. Baker \& S. Kirk) (3rd edn), pp. 13-27. Abingdon: Radcliffe Medical Press.

BAKER, M. R. (2001b) NHS R\&D: the future prospects. In Research and Development for the NHS: Evidence, Evaluation and Effectiveness (eds M. R. Baker \& S. Kirk) (3rd edn), pp. 210-214. Abingdon: Radcliffe Medical Press.

BIOSCIENCE INNOVATION AND GROWTH TEAM (2003) Bioscience 2015: Improving National Health Increasing National Wealth. London: Department of Trade and Industry.

CENTRAL RESEARCHAND DEVELOPMENT COMMITTEE OF TH DEPARTMENT OF HEALTH (1999) Strategic Review of the NHS R\&D Levy. London: Department of Health.

CHILVERS, C., SPIERS, S. \& BARNES, S (2005) NHS research and development in mental health. In Research and Development in Mental Health: Theory, Frameworks and Models (eds D. Sallah \& M. Clark), pp.179-203. London: Elsevier.
COUNCIL OF HEADS OF MEDICAL SCHOOLS (2004) Clinical Academic Staffing Levels in UK Medical and Dental Schools. London: CHMS.

CULYER, A. (1994) Supporting Research and Development in the NHS. Report of the Department of Health Research and Development Task Force. London: Stationery Office.

DEPARTMENT OF HEALTH (1999a) NHS R\&D Strategic Review: Mental Health Topic Working Group. London: Department of Health.

DEPARTMENT OF HEALTH (1999b) The National Service Framework for Mental Health: Modern Standards and Service Models. London: Department of Health.

DEPARTMENT OF HEALTH (2000) Research and Development for a First Class Service: R\&D Funding in the New NHS. London: Department of Health.

DEPARTMENT OF HEALTH (2002)

Strategic Reviews of Research and Development - Mental Health Main

Report. London: Department of Health.

DEPARTMENT OF HEALTH (2004) The National Service Framework for Mental Health - Five Years on. London: Department of Health.

DEPARTMENT OF HEALTH (2005)

Research Governance Framework for Health and Social Care (2nd edn). London: Department of Health.

HOUSE OF LORDS SELECT COMMITTEE ON SCIENCE AND TECHNOLOGY (1988) Priorities in Medical Research. London: Stationery Office.

KIRK, S. (2001) The NHS R\&D strategy. In Research and Development for the NHS Evidence, Evaluation and

Effectiveness (eds M. R. Baker \& S. Kirk) (3rd edn), pp.1-11. Abingdon: Radcliffe Medical Press.

LEWISON, G. \& WILCOX-JAY, K. (2002) Research outputs of mental health from 15 countries. In Strategic Reviews of Research and Development - Mental Health Report, pp.11-40. Appendices. London: Department of Health.

NATIONAL CANCER RESEARCH NSTITUTE (2002) Strategic Analysis 2002: An Overview of Cancer Research in the UK Directly Funded by the NCRI Partner Organisations. London: NCRI. NATIONAL INSTITUTE FOR MENTAL HEALTH IN ENGLAND (2004) Complex Evaluations in Mental Health Research - Report from a Day Conference. http://kc.nimhe.org.uk/ upload/complex $\% 20$ evals $\% 20$ workshop\%20report.pdf.

NEWTON, E. \& BIRCHWOOD, M. (2005) Early intervention in psychosis: research, clinical practice and service reform. In Research and Development in Mental Health: Theory, Frameworks and Models (eds D. Sallah \& M. Clark) pp. 265-294. London: Elsevier.

PANG,T., SADANA, R., HANNEY, $\mathrm{S}$. et al (2003) Knowledge for better health: a conceptual framework and foundation for health research systems. Bulletin of the World Health Organization, 81, 815-820.

PECKHAM, M. (1991a) Research and development for the National Health Service Lancet, 338, 367-371.

PECKHAM, M. (1991b) Research for Health. London: Department of Health. RESEARCH FOR PATIENT BENEFIT WORKING GROUP (2004) Research for Patient Benefit Working Group - Final Report. London: Department of Health.

SADANA, R. \& PANG T (2004) Current approaches to national health research system analysis: a brief overview of the WHO health research system analysis initiative. Ciência e Saúde Coletiva, 9 , 351-362.

THORNICROFT, G., BINDMAN, J, GOLDBERG, D., et al (2002) Researchable questions to support evidence-based mental health policy concerning adult mental illness. Psychiatric Bulletin, 26, 364-367.

\section{UK CLINICAL RESEARCH}

COLLABORATION (2004) lgniting the Potential: An Introduction to the UK Clinical Research Collaboration. London: UKCRC.
* Michael Clark Manager for Mental Health R\&D Portfolio, Department of Health, c/oThe Beeches, Penn Hospital, Penn Road, Wolverhampton WV4 5NH, e-mail: Michael.clark@wolvespct.nhs.uk, Clair Chilvers Director of Mental Health R\&D and Director of R\&D, National Institute for Mental Health in England, London

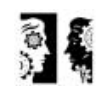

editorial 